\title{
Hyperoxia during extracorporeal cardiopulmonary resuscitation for refractory cardiac arrest is associated with severe circulatory failure and increased mortality
}

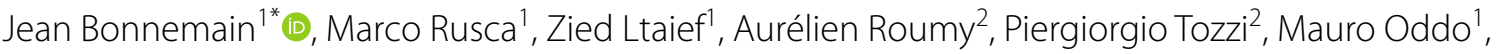
Matthias Kirsch ${ }^{2}$ and Lucas Liaudet ${ }^{1}$

\begin{abstract}
Background: High levels of arterial oxygen pressures $\left(\mathrm{PaO}_{2}\right)$ have been associated with increased mortality in extracorporeal cardiopulmonary resuscitation (ECPR), but there is limited information regarding possible mechanisms linking hyperoxia and death in this setting, notably with respect to its hemodynamic consequences. We aimed therefore at evaluating a possible association between $\mathrm{PaO}_{2}$, circulatory failure and death during ECPR.

Methods: We retrospectively analyzed 44 consecutive cardiac arrest (CA) patients treated with ECPR to determine the association between the mean $\mathrm{PaO}_{2}$ over the first $24 \mathrm{~h}$, arterial blood pressure, vasopressor and intravenous fluid therapies, mortality, and cause of deaths.

Results: Eleven patients (25\%) survived to hospital discharge. The main causes of death were refractory circulatory shock (46\%) and neurological damage (24\%). Compared to survivors, non survivors had significantly higher mean $24 \mathrm{~h} \mathrm{PaO}_{2}(306 \pm 121 \mathrm{mmHg}$ vs $164 \pm 53 \mathrm{mmHg}, \mathrm{p}<0.001)$, lower mean blood pressure and higher requirements in vasopressors and fluids, but displayed similar pulse pressure during the first $24 \mathrm{~h}$ (an index of native cardiac recovery). The mean $24 \mathrm{~h} \mathrm{PaO}_{2}$ was significantly and positively correlated with the severity of hypotension and the intensity of vasoactive therapies. Patients dying from circulatory failure died after a median of $17 \mathrm{~h}$, compared to a median of $58 \mathrm{~h}$ for patients dying from a neurological cause. Patients dying from neurological cause had better preserved blood pressure and lower vasopressor requirements.
\end{abstract}

Conclusion: In conclusion, hyperoxia is associated with increased mortality during ECPR, possibly by promoting circulatory collapse or delayed neurological damage.

Keywords: Extracorporeal cardiopulmonary resuscitation (ECPR), Veno-arterial membrane oxygenation (VA-ECMO), Cardiac arrest, Hyperoxia

*Correspondence: jean.bonnemain@chuv.ch

${ }^{1}$ The Service of Adult Intensive Care Medicine, Lausanne University Hospital and University of Lausanne, Rue du Bugnon 46, 1011 Lausanne, Switzerland

Full list of author information is available at the end of the article

\section{Background}

Extracorporeal cardiopulmonary resuscitation (ECPR) for refractory out-of-hospital (OHCA) or in-hospital (IHCA) cardiac arrest has gained growing interest over the past years $[1,2]$. However, recent multicenter registries reported relatively low favorable neurological outcome and survival in heterogeneous cohorts of patients 
treated with ECPR [3, 4], implying that this strategy should be limited to highly selected patients [4-6]. Besides patient selection, improving the quality of postcardiac arrest care might also be key to improve ECPR outcome. The restoration of systemic oxygenated blood flow after cardiac arrest may trigger reperfusion injury, largely mediated by the generation of oxidants and free radicals [7], whose magnitude may be influenced by the arterial partial pressure of oxygen $\left(\mathrm{PaO}_{2}\right)$ during reperfusion $[8,9]$. In conventional CPR, an association between hyperoxia (defined as supranormal $\mathrm{PaO}_{2}$ caused by high fractions of inspired oxygen, with a cut-off value of $300 \mathrm{mmHg}$ frequently used in clinical studies) after return of spontaneous circulation (ROSC) and outcome has been indeed reported in large observational studies $[10,11]$.

Patients undergoing ECPR may be exposed to significant hyperoxia, given the ease to oxygenate blood through the oxygenator [12], and recent retrospective analyses indicated that hyperoxia during the first $24 \mathrm{~h}$ of ECPR was associated with reduced survival [13, 14]. One of these studies reported a significant association between circulatory shock during the first $24 \mathrm{~h}$ and mortality [14], whereas another study showed that most deaths (88\%) occurred during the first $48 \mathrm{~h}$ and were related to multiple organ failure [13]. These findings suggest the hypothesis that early hyperoxia during ECPR may precipitate cardiovascular dysfunction leading to organ failure and death, by exacerbating post-resuscitation disease related to reperfusion injury. To address this hypothesis, we sought to determine the potential association between hyperoxia during the first $24 \mathrm{~h}$ of ECPR and the severity of hemodynamic failure, as well as its possible association with mortality in a cohort of 44 patients treated with ECPR for refractory IHCA and OHCA. In addition, since hyperoxia-mediated toxicity is largely related to the generation of oxygen free radicals, one can hypothesize that a longer duration of hyperoxia might be associated with a cumulative exposure to such species, hence greater toxicity, as recently shown by Roberts et al. in a prospective study on hyperoxia in cardiac arrest [11]. Therefore, instead of relying on a single value of $\mathrm{PaO}_{2}$, we averaged the values of several $\mathrm{PaO}_{2}$ measurements during the first $24 \mathrm{~h}$ of ECPR, in order to take into account the duration of exposure to elevated $\mathrm{PaO}_{2}$ levels during this period of time. We then evaluated a possible association between $\mathrm{PaO}_{2}$ levels, circulatory failure and death during ECPR.

\section{Methods}

\section{Study setting}

This study was approved by our ethical committee (Commission Cantonale d'Ethique de la Recherche sur l'Etre
Humain/CER-VD-Nr: 2017-01,184), as a retrospective use of clinical data with waiver of consent (CER-VDNr: 2017-011,184), and conforms to the STROBE statement for the report of observational studies. All methods were performed in accordance with the relevant guidelines and regulations. The cohort included 44 consecutive patients hospitalized in our 35-bed multidisciplinary ICU for refractory, non-traumatic and non-hypothermic, OHCA and IHCA treated with ECPR from June 2017 to June 2019. During this period, our internal recommendations for starting ECPR were: refractory OHCA or IHCA; no flow $<5 \mathrm{~min}$; low flow $<80 \mathrm{~min}$; age $<75$ years; absence of major co-morbidities; absence of Do Not Resuscitate order. A subset of patients of the current cohort were also included in an unrelated study evaluating automated pupillometry during Veno-Arterial ECMO (VA-ECMO) for various indications [15].

\section{Treatment strategy}

The insertion of venous and arterial femoral cannulas was performed in the hospital by a cardiac surgeon. Initial VA-ECMO settings included a sweep fraction of oxygen $\left(\mathrm{F}_{\mathrm{S}} \mathrm{O} 2\right)$ of $100 \%$ and a pump setting for a target blood flow of 40-60 ml $/ \mathrm{kg}$, using the Maquet Cardiohelp ECLS system ${ }^{\circledR}$. Sweep gas flow was adapted to maintain normal $\mathrm{PaCO}_{2}$. Systemic anticoagulation (intravenous heparin) initiated at the end of surgery was maintained to achieve an anti-Xa activity of $0.3-0.5$. A coronary angiography was performed at the discretion of the in charge physicians, when an ischemic origin of cardiac arrest was strongly suspected, according to internal recommendations. Noradrenaline (NA) and Adrenaline (Adre) were given to maintain mean blood pressure $(\mathrm{BP}) \geq 65 \mathrm{mmHg}$. Intravenous (IV) fluids were administered to maintain the target blood flow. Mechanical ventilation was performed with a tidal volume of $6 \mathrm{ml} / \mathrm{kg}$, rate of 10-15/ min and PEEP of 6-10 $\mathrm{cm} \mathrm{H}_{2} \mathrm{O}$. Both $\mathrm{FiO}_{2}$ and $\mathrm{FsO}_{2}$ were set by default at $100 \%$ on ECPR initiation. Following these initial settings, decisions to reduce $\mathrm{FiO}_{2}$ or/and $\mathrm{FsO}_{2}$ were entirely at the discretion of the treating physicians, without specific recommendation. Sedation was maintained with Propofol $(2-4 \mathrm{mg} / \mathrm{kg} / \mathrm{h})$ or Midazolam $(0.05-0.15 \mathrm{mg} / \mathrm{h})$. Targeted temperature management at $35-36{ }^{\circ} \mathrm{C}$ for $24 \mathrm{~h}$ was implemented in all patients. Criteria for discontinuing VA-ECMO were the absence of cardiac function recovery, intractable circulatory shock, or evidence of severe neurological injury (major stroke on cerebral imaging or evidence of severe anoxic brain injury according to a multimodal outcome prediction, combining neurological examination, electrophysiological data, and plasma levels of serum neuron-specific enolase (NSE), as described in [16]). Criteria for weaning of VA-ECMO included a mean $\mathrm{BP}>65 \mathrm{mmHg}$, left ventricle 
ejection fraction $>20 \%$ and aortic velocity time integral (VTI) $>10 \mathrm{~cm}$ on transthoracic echocardiography, under minimal vasopressor (Norepinephrine $\leq 0.1 \mu \mathrm{g} / \mathrm{kg} / \mathrm{min}$ ) and inotropic (Dobutamine $<4 \mu \mathrm{g} / \mathrm{kg} / \mathrm{min}$ ) support and ECMO flow (1L/min).

\section{Data collection}

Demographic variables included age, sex, location of CA (OHCA, IHCA), initial rhythm, duration of no flow and low flow (total duration of CPR before ECMO initiation), SAPS 2 score, ICU and hospital length of stay, duration of ECMO treatment, proportion of patients undergoing coronary angiography and angioplasty (PTCA), as well as the causes of death.

Hemodynamic variables included: (A) Mean arterial blood pressure (mean BP, obtained via an arterial catheter in all but 3 patients), from which we computed the average from all measurements performed each $2 \mathrm{~h}$ during the first $24 \mathrm{~h}$ (or until death if it occurred before $24 \mathrm{~h}$ ). (b) Pulse pressure (systolic minus diastolic blood pressure), determined during the first $24 \mathrm{~h}$ as an indirect indicator of native cardiac output recovery [17], which was averaged from values obtained at 2, 6, 12 and $24 \mathrm{~h}$ (or until death if it occurred before $24 \mathrm{~h}$ ). (C) The amount of catecholamines, fluids, packed red blood cells and fresh frozen plasma administered (first $72 \mathrm{~h}$ ).

Blood gas data were obtained from an indwelling intraarterial catheter, whose position was recorded (right radial, left radial or femoral). The values of $\mathrm{PaO}_{2}$ measured at 5 different times of ECPR (first $15 \mathrm{~min}, 2 \mathrm{~h}, 6 \mathrm{~h}$, $12 \mathrm{~h}$ and $24 \mathrm{~h}$ ) were averaged as the mean $24 \mathrm{~h} \mathrm{PaO}_{2}$ (in patients dying before $24 \mathrm{~h}$, mean $\mathrm{PaO}_{2}$ was computed from values obtained during the time spent under ECPR until death). Arterial blood lactate was determined in the first arterial blood sampling (first 15 min of ECPR).

\section{Data analysis}

Continuous variables are expressed as means $\pm S D$, or medians and interquartile ranges (IQR), and categorical data as absolute numbers and percentages. All comparisons were done using the Wilcoxon's rank sum test for continuous variables and the chi-square test for categorical variables. We determined which variables were associated with survival using univariate logistic regression analysis for continuous variables and contingency analysis with Pearson's test for categorical variables. To evaluate the association of hyperoxia with mortality, multivariable logistic regression was applied. We first considered a model including only co-variables significantly associated with mortality in univariate analysis (low flow duration, first arterial lactate, mean $\mathrm{BP}$ and mean $\mathrm{PaO}_{2}$ ). We next applied a model including co-variables commonly considered as important clinical predictors of poor outcome, including age, low flow and no flow duration, shockable rhythm, the duration of ECMO, as well as mean $\mathrm{PaO}_{2}$. In both models, hospital mortality was the response binomial variable. Odds ratios (ORs) with $95 \%$ $\mathrm{CI}$ were calculated (for continuous variables, ORs were calculated per unit change of each variable), and Wald statistics was used to assess the significance of each variable. Furthermore, due to the relatively low number of events in our cohort and the inherent risk of overestimating regression coefficients [18], we complemented this analysis by running several logistic regressions using only mean $\mathrm{PaO}_{2}$ and a second co-variable at a time (including co-variable with a $\mathrm{p}$ value $<0.2$ in the multivariable logistic regression: no flow, low flow, and shockable rhythm). To control for possible type I error, we introduced a Bonferroni adjustment for assessing significance in these 3 models (thus, a p value of $0.05 / 3=0.016$ was used as the significance limit in these analyses). To determine a possible association between $\mathrm{PaO}_{2}$ and circulatory failure, we performed bivariate analyses and simple linear regressions between mean $\mathrm{PaO}_{2}$ and mean blood pressure and between mean $\mathrm{PaO}_{2}$ and the amount of vasopressive catecholamines administered, with calculation of the Pearson $\mathrm{r}$ coefficient. To determine the influence of the arterial catheter position on $\mathrm{PaO}_{2}, \mathrm{PaO}_{2}$ values obtained in the different catheter positions were compared using Wilcoxon rank test. The JMP software, version 15, was used for all the analyses, and a p value $<0.05$ was considered statistically significant.

\section{Results}

The characteristics of patients and differences between survivors and non survivors are shown in Table 1 . No patient in our cohort displayed ROSC before ECMO initiation. For the whole cohort, in-hospital survival was 25\% (11pts), including OHCA: $7 / 27=26 \%$ and IHCA: $4 / 17=24 \%(\mathrm{p}=0.86)$. Survivors had lower SAPS 2 scores, longer LOS and ECPR duration. There were no differences in terms of location of CA, initial rhythm, no flow duration and $\mathrm{PaCO}_{2}$ levels, whereas low flow duration, first arterial lactate and intravenous fluids administration were significantly higher in non survivors.

In two patients dying early after ECPR initiation, arterial blood samples were not obtained. Non-survivors had significantly higher mean $\mathrm{PaO}_{2}$ during the first $24 \mathrm{~h}$ (Table 1 and Fig. 1). At each time point, the values of $\mathrm{PaO}_{2}$ in non-survivors vs survivors were: ECMO initiation: $444 \pm 107$ vs $352 \pm 136 \mathrm{mmHg} \quad(\mathrm{p}=0.03)$; 2 h: $287 \pm 175$ vs $164 \pm 108 \mathrm{mmHg}(\mathrm{p}=0.07) ; 6 \mathrm{~h}$ : $253 \pm 148$ vs $125 \pm 78 \mathrm{mmHg}(\mathrm{p}=0.02) ; 12 \mathrm{h:} 161 \pm 111$ vs $85 \pm 22 \mathrm{mmHg}(\mathrm{p}=0.004) ; 24 \mathrm{~h}: 121 \pm 44$ vs $94 \pm 21 \mathrm{mmHg}(\mathrm{p}=0.02)$. At the respective time-points, the number of measurements were 11 in survivors and 
Table 1 Characteristics of patients

\begin{tabular}{|c|c|c|c|c|}
\hline & $\begin{array}{l}\text { All pts } \\
(n=44)\end{array}$ & $\begin{array}{l}\text { Non survivors } \\
(n=33)\end{array}$ & $\begin{array}{l}\text { Survivors } \\
(n=11)\end{array}$ & $p$ value \\
\hline Age (years), mean (SD) & $52(14)$ & $54(12)$ & $48(19)$ & 0.456 \\
\hline Male sex, n (\%) & $31(70)$ & $24(73)$ & $7(63)$ & 0.567 \\
\hline SAPS 2, mean (SD) & $83(13)$ & $85(14)$ & $76(6)$ & 0.003 \\
\hline ICU LOS (days), median (IQR) & $2.6(18.8)$ & $1.5(4.3)$ & $22.9(28.8)$ & $<0.001$ \\
\hline HOSP LOS, (days), median (IQR) & $2.8(27.3)$ & $1.6(4.2)$ & $51.4(38.0)$ & $<0.001$ \\
\hline ECMO Weaning, n (\%) & $15(34)$ & $4(12)$ & $11(100)$ & $<0.001$ \\
\hline Survival (Hospital), n (\%) & $11(25)$ & $0(0)$ & $11(100)$ & \\
\hline ECMO duration (hours), median (IQR) & $43(106)$ & $28(106)$ & $81(74)$ & 0.024 \\
\hline Location of $\mathrm{CA}$ & & & & 0.858 \\
\hline $\mathrm{OHCA}, \mathrm{n}(\%)$ & $27(61)$ & $20(65)$ & $7(63)$ & \\
\hline$\| \mathrm{HCA}, \mathrm{n}(\%)$ & $17(39)$ & $13(35)$ & $4(37)$ & \\
\hline Initial rhythm & & & & 0.141 \\
\hline$V F, n(\%)$ & $23(52)$ & $16(49)$ & $7(64)$ & \\
\hline PEA, n (\%) & $14(32)$ & $11(33)$ & $3(27)$ & \\
\hline Asystole, n (\%) & $6(14)$ & $6(18)$ & $0(0)$ & \\
\hline Unknown, n (\%) & $1(2)$ & $0(0)$ & $1(9)$ & \\
\hline Shockable Rhythm & $23(52)$ & $16(48)$ & $7(64)$ & 0.214 \\
\hline No flow (minutes), mean (SD) & $1.2(2.0)$ & $1.1(2.0)$ & $1.5(2.2)$ & 0.572 \\
\hline Low flow (minutes), mean (SD) & $68(23)$ & $73(22)$ & $51(18)$ & 0.005 \\
\hline Mean $\mathrm{PaO}_{2}$ (first $24 \mathrm{~h}, \mathrm{mmHg}$ ), mean (SD) & $269(124)$ & $306(121)$ & $164(53)$ & 0.001 \\
\hline Mean $\mathrm{PaCO}_{2}$ (first $24 \mathrm{~h}, \mathrm{mmHg}$ ), mean (SD) & $37(6)$ & $36(7)$ & $38(3)$ & 0.525 \\
\hline First lactate (mmol/L), mean (SD) & $13.4(5.9)$ & $14.9(5.8)$ & $9.4(4.1)$ & 0.004 \\
\hline Mean BP (first 24 h), mean (SD) & $67(12)$ & $64(12)$ & $75(5)$ & 0.007 \\
\hline Pulse Pressure (first 24 h), mean (SD) & $20(13)$ & $18(12)$ & $25(13)$ & 0.149 \\
\hline Coronarography, n (\%) & $22(50)$ & $16(48)$ & $6(54)$ & 0.728 \\
\hline PTCA, n (\%) & $17(39)$ & $11(33)$ & $6(54)$ & 0.211 \\
\hline NA ( $\mu \mathrm{g} / \mathrm{kg} / \mathrm{min}$, first $72 \mathrm{~h}$ ), median (IQR) & $0.25(0.44)$ & $0.37(0.54)$ & $0.12(0.13)$ & 0.006 \\
\hline ADRE, ( $\mu \mathrm{g} / \mathrm{kg} / \mathrm{min}$, first $72 \mathrm{~h})$, median (IQR) & $0.02(0.13)$ & $0.06(0.20)$ & $0.00(0.04)$ & 0.043 \\
\hline Total catecholamines (NA + ADRE, first 72 h) & $0.36(0.73)$ & $0.54(0.67)$ & $0.12(0.16)$ & 0.002 \\
\hline Cristalloid (ml/kg/h, first 72 h), mean (SD) & $6.0(9.8)$ & $7.3(11.2)$ & $2.4(0.8)$ & 0.023 \\
\hline Packed RBC ( $\mathrm{n}$, first 72 h), mean (SD) & $5.2(4.7)$ & $5.5(4.8)$ & $4.4(4.4)$ & 0.449 \\
\hline FFP (n, first 72 h), mean (SD) & $2.4(3.0)$ & $2.6(3.1)$ & $1.6(2.7)$ & 0.294 \\
\hline
\end{tabular}

$A D R E$ adrenaline, $B P$ blood pressure, ECMO extra-corporeal membrane oxygenation, FFP fresh frozen plasma, ICU intensive care unit, IHCA in-hospital cardiac arrest, LOS length of stay, NA noradrenaline, OHCA out-of-hospital cardiac arrest, PEA pulseless electrical activity, PTCA percutaneous transluminal coronary angioplasty, RBC red blood cells, SAPS simplified acute physiology score, VF ventricular fibrillation

31, 27, 27, 22 and 18 in non-survivors. Non-survivors also displayed lower mean blood pressure during the first $24 \mathrm{~h}$, and received significantly more vasopressive catecholamines (Table 1 and Fig. 2A, B). Pulse pressure during the first $24 \mathrm{~h}$ was not different between non-survivors and survivors (Table 1 and Fig. $2 \mathrm{C}$ ). The mean $\mathrm{PaO}_{2}$ value during the first $24 \mathrm{~h}$ displayed a significant negative correlation with mean blood pressure (Fig. 2D) and positive correlation with total amount of vasopressors (NA + Adre, in $\mu \mathrm{g} / \mathrm{kg} / \mathrm{min}$ during the first 3 days, Fig. 2E).

Variables associated with in-hospital mortality at the $5 \%$ level in univariate analysis (Table 2) included the duration of low flow, mean $\mathrm{PaO}_{2}$, the first arterial lactate concentration, the amounts of catecholamines and IV fluids administered, as well as mean blood pressure during the first $24 \mathrm{~h}$. Table 3 shows the results of the two models of multivariable logistic regression analyses, which indicate that mean $\mathrm{PaO}_{2}$ was the only co-variate showing a $\mathrm{p}$ value $<0.05$ for the association with mortality in both models. The results of the logistic regressions including only 2 co-variates (mean $\mathrm{PaO}_{2}$ and low flow; mean $\mathrm{PaO}_{2}$ and no flow; mean $\mathrm{PaO}_{2}$ and initial rhythm), also show an association between mean $\mathrm{PaO}_{2}$ and mortality following Bonferroni correction. 


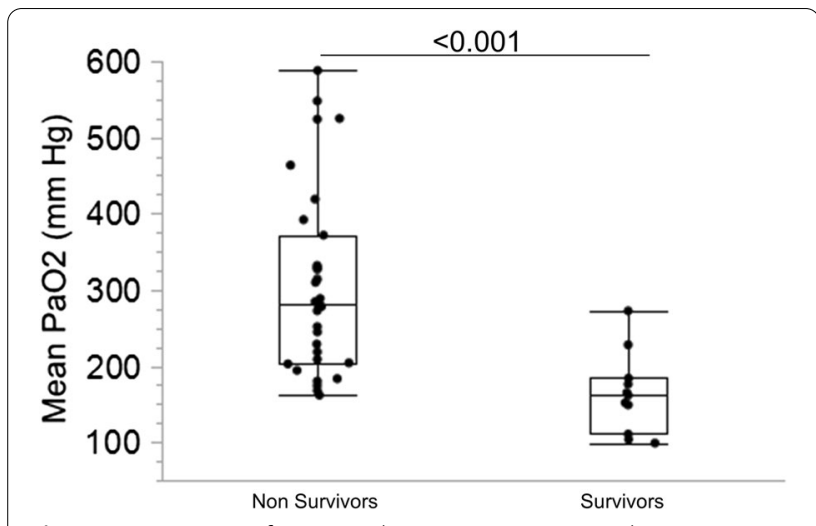

Fig. 1 Comparison of mean $24 \mathrm{~h} \mathrm{PaO}_{2}$ in survivors and non survivors

The causes of refractory CA included acute myocardial ischemia ( $\mathrm{n}=24,55 \%$ of patients), acute hypoxic CA $(\mathrm{n}=4,9 \%)$, primary arrhythmia $(\mathrm{n}=3,7 \%)$, acute pulmonary embolism $(n=3,7 \%)$, toxic/metabolic origin $(n=3$, $7 \%$, including one cocaine intoxication, one aluminium phosphorus intoxication and one severe metabolic acidosis), heart transplant rejection $(\mathrm{n}=2 ; 4 \%)$, undetermined cause $(n=2,4 \%)$, and other causes $(n=3,7 \%$, including one intraoperative $\mathrm{CA}$, one pericardial tamponade and one subarachnoid hemorrhage). The two main causes of death under ECPR were profound circulatory shock ( $n=15,46 \%$ of patients) and neurological injury (severe anoxic encephalopathy or major stroke, $n=8,24 \%$ of patients). Other causes of death included hemorrhagic shock $(n=3)$. Multiple organ failure $(n=4)$, septic shock $(n=2)$ and technical issue $(n=1$, related to an intractable failure to obtain an adequate venous inflow, possibly due to extensive thrombosis in the inferior vena cava). Comparisons between patients dying from circulatory or neurological causes are shown in Fig. 3. Low flow was not statistically different in the two groups (Fig. 3A). Patients dying from circulatory cause had significantly higher initial lactate (Fig. 3B) and shorter ICU LOS (Fig. 3C). The mean $\mathrm{PaO}_{2}$ during the first $24 \mathrm{~h}$ was not different $(\mathrm{p}=0.1$ between both groups, Fig. 3D). Patients with neurological death had significantly higher mean BP during the first $24 \mathrm{~h}$ (Fig. 3E) and received significantly less vasopressive catecholamines (Fig. 3F).

Mean $\mathrm{PaO}_{2}$ measured via a right arterial catheter was not different from that measured from a left radial catheter, but was lower than that measured via a femoral catheter, and mean $\mathrm{PaO}_{2}$ measured from a left radial catheter

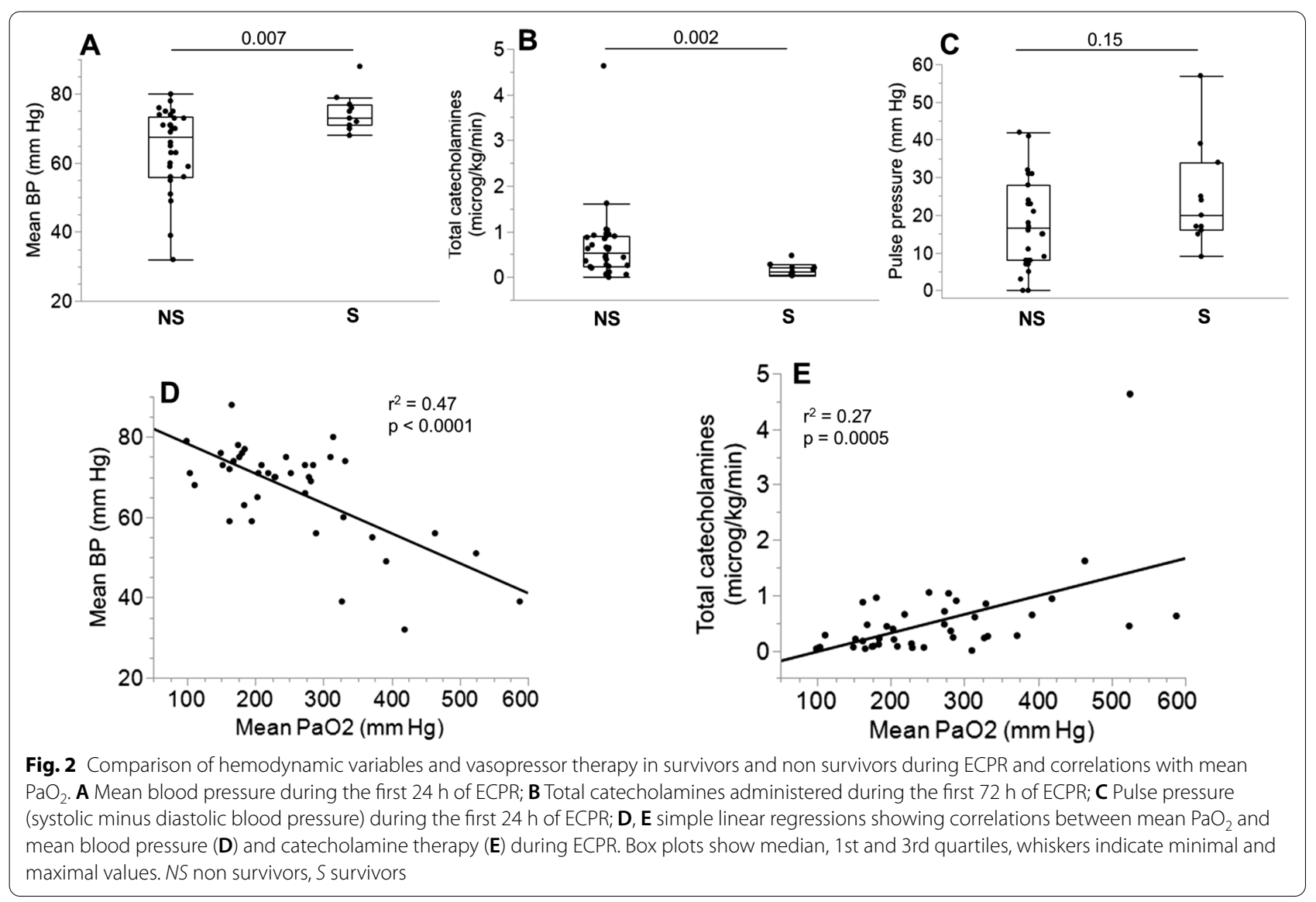


Table 2 Variables associated with in-hospital mortality (univariate analysis)

\begin{tabular}{lcr}
\hline Variable & OR [95\% Cl] & p value \\
\hline Age & $1.03[0.98-1.09]$ & 0.244 \\
Localization of CA (OHCA vs IHCA) & $0.88[0.20-3.54]$ & 0.858 \\
Initial rhythm (VF vs non VF) & $0.40[0.08-1.73]$ & 0.226 \\
SAPS II & $1.06[0.99-1-15]$ & 0.052 \\
No flow duration & $0.91[0.66-1.26]$ & 0.580 \\
Low flow duration & $1.06[1.02-1.11]$ & 0.003 \\
Lactate at ECMO initiation & $1.22[1.06-1.46]$ & 0.005 \\
Mean PaO ${ }_{2}$ first 24 h on ECMO & $1.03[1.01-1.06]$ & $<0.001$ \\
Mean PaCO ${ }_{2}$ first 24 h on ECMO & $0.95[0.82-1.08]$ & 0.462 \\
Mean BP (first 24 h) & $0.84[0.72-0.98]$ & 0.001 \\
Pulse Pressure (first 24 h) & $0.96[0.90-1.01]$ & 0.129 \\
Total catecholamines (NA + ADRE) & $4.51[1.70-15.68]$ & 0.012 \\
Total Cristalloid & $1.67[0.96-2.89]$ & 0.005 \\
Catheter position (right RA vs other) & $2.10[0.53-9.54]$ & 0.297 \\
Coronarography & $0.78[0.32-5.23]$ & 0.728 \\
PTCA & $0.42[0.10-1.67]$ & 0.217 \\
Packed RBC & $1.06[0.91-1.26]$ & 0.459 \\
FFP & $1.14[0.87-1.49]$ & 0.322 \\
\hline
\end{tabular}

Univariate analysis of variables associated with in-hospital mortality. Data are shown as p values and odds ratio (OR) with $95 \%$ confidence interval (Cl)

ADRE adrenaline, $C A$ cardiac arrest, ECMO extra-corporeal membrane oxygenation, FFP fresh frozen plasma, IHCA in-hospital cardiac arrest, NA noradrenaline, OHCA out-of-hospital cardiac arrest, PTCA percutaneous transluminal coronary angioplasty, $R A$ radial artery, $R B C$ red blood cells, SAPS simplified acute physiology score, $V F$ ventricular fibrillation

was not different from that measured via a femoral catheter (Fig. 4A). When comparing mean $\mathrm{PaO}_{2}$ between survivors and non survivors according to the catheter position, values were significantly lower in survivors for each position of the arterial catheter (Fig. 4B).

\section{Discussion}

\section{Background and previous work}

The restoration of systemic oxygenated blood flow after a prolonged period of hypoxia may trigger widespread reperfusion injury. A key mechanism of reperfusion injury is the generation of oxidants and free radicals [19], whose flux increases in proportion with the local $\mathrm{PO}_{2}$ [20-22], implying an increased risk of oxidant-mediated damage at higher $\mathrm{PO}_{2}$ during reperfusion [23]. In the setting of ECPR, the risk of hyperoxia is particularly elevated, due to the ease of oxygenating blood through the membrane oxygenator $[5,12]$, and a few retrospective studies have indeed reported a negative impact of hyperoxia on survival after ECPR [13, 14, 24]. In a retrospective cohort of 291 ECPR patients, Chang et al. reported that a first $\mathrm{PaO}_{2}$ value during the first $24 \mathrm{~h}$ after ECPR initiation between 77 and $220 \mathrm{mmHg}$, was significantly associated with neurologically intact survival in comparison to higher values
Table 3 Variables associated with in-hospital mortality (multivariable analysis)

\begin{tabular}{|c|c|c|c|}
\hline Variable & Odds ratio & $95 \% \mathrm{Cl}$ & $p$ value \\
\hline \multicolumn{4}{|c|}{$\begin{array}{l}\text { (a) Model using co-variables significantly associated with mortality in } \\
\text { univariate analysis }\end{array}$} \\
\hline Low flow duration & 1.03 & $0.96-1.11$ & 0.39 \\
\hline First Lactate & 1.19 & $0.92-1.53$ & 0.18 \\
\hline Mean BP & 0.86 & $0.69-1.07$ & 0.17 \\
\hline Mean $\mathrm{PaO}_{2}$ & 1.02 & $1.01-1.05$ & 0.02 \\
\hline \multicolumn{4}{|c|}{$\begin{array}{l}\text { (b) Model using co-variables frequently associated with mortality in univari- } \\
\text { ate analysis }\end{array}$} \\
\hline Age & 1.04 & $0.92-1.17$ & 0.55 \\
\hline No Flow duration & 0.01 & $0.01-1.38$ & 0.09 \\
\hline Low flow duration & 1.26 & $0.99-1.59$ & 0.06 \\
\hline ECMO duration & 1.01 & $0.99-1.03$ & 0.25 \\
\hline Shockable rhythm & 0.01 & $0.01-3.29$ & 0.12 \\
\hline Localization (IH vs OH) & 0.05 & $0.01-7.32$ & 0.24 \\
\hline Mean $\mathrm{PaO}_{2}$ & 1.07 & $1.01-1.13$ & 0.03 \\
\hline \multicolumn{4}{|c|}{ (c) Models with 2 co-variables } \\
\hline Mean $\mathrm{PaO}_{2}$ & 1.04 & $1.02-1.08$ & 0.009 \\
\hline No flow & 0.62 & $0.31-1.07$ & 0.121 \\
\hline Mean $\mathrm{PaO}_{2}$ & 1.02 & $1.01-1.06$ & 0.011 \\
\hline Low flow & 1.03 & $0.98-1.11$ & 0.232 \\
\hline Mean $\mathrm{PaO}_{2}$ & 1.03 & $1.01-1.06$ & 0.013 \\
\hline Shockable rhythm & 0.42 & $0.06-2.86$ & 0.383 \\
\hline
\end{tabular}

$\mathrm{Cl}$ confidence interval. Odds ratio for continuous variables are calculated per unit change for each variable ( $1 \mathrm{mmol} / \mathrm{L}$ for lactate, $1 \mathrm{mmHg}$ for mean BP, 1 y for age, $1 \mathrm{~min}$ for no flow and low flow duration, $1 \mathrm{~h}$ for ECMO duration, $1 \mathrm{mmHg}$ for mean $\mathrm{PaO}_{2}$ )

[14]. In a retrospective cohort of 66 patients undergoing ECPR for refractory OHCA, Halter et al. reported a significant association between $\mathrm{PaO}_{2}$ measured at $30 \mathrm{~min}$ after ECPR initiation and 28 days mortality. Using a threshold value of $\mathrm{PaO}_{2}$ of $300 \mathrm{mmHg}$ to define hyperoxia, the odds ratio for 28 days mortality was 4.07 [13]. In our study, non survivors displayed a higher mean $24 \mathrm{~h}$ $\mathrm{PaO}_{2}$, lower mean blood pressure, higher needs in vasopressors, and profound circulatory shock was the primary cause of death in a majority of non survivors. Taken together, these findings suggest that severe vascular failure with refractory circulatory shock may represent an important mechanism of hyperoxia toxicity during ECPR.

\section{Hyperoxia toxicity in ECPR}

Hyperoxia results in an increased vascular generation of superoxide $\left(\mathrm{O}_{2}{ }^{-}\right)$, which reacts rapidly with nitric oxide (NO) to form peroxynitrite, that can trigger significant vascular contractile failure through a number of processes [25-27]. In addition, oxidants such as peroxynitrite promote the expression of multiple inflammatory cytokines and mediators [28-31], which also reduce 

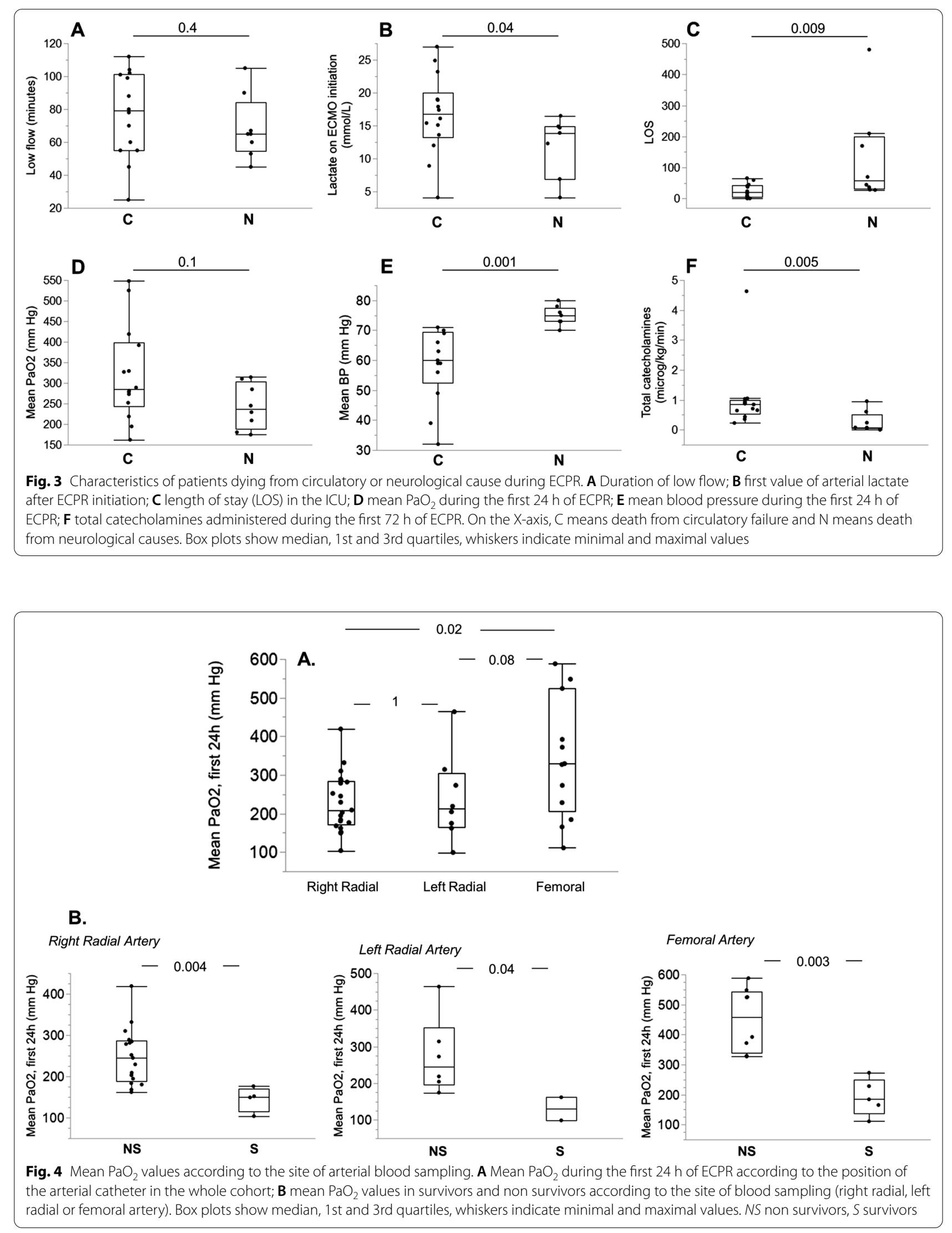
vascular tone and may precipitate hypotension. These effects may contribute to foster a sepsis-like state, characterized by an irreversible loss of vascular contractility and refractory hypotension with negative prognostic impact after prolonged resuscitation and ECPR, as recently reported by Jouffroy et al. [32]. Obviously, the formation of peroxynitrite and other oxidants, together with the generation of inflammatory mediators, at different levels of $\mathrm{PaO}_{2}$ during ECPR, should be evaluated in future investigations to explore these mechanisms.

\section{Importance of the localization of arterial blood sampling in ECPR}

A critical aspect in the interpretation of arterial blood gases during peripheral VA-ECMO is the localization of arterial blood sampling and right radial artery sampling is recommended [33], owing to the risk of upper body hypoxia in case of cardiac recovery and impaired pulmonary gas exchange [34]. Accordingly, we found that $\mathrm{PaO}_{2}$ was lower when measured from a right radial artery than from a femoral artery, while it did not differ from values obtained from the left radial artery. One could therefore argue that the lower $\mathrm{PaO}_{2}$ in survivors might reflect an earlier recovery of native cardiac function, but this appears unlikely in view of the similar values of pulse pressure, an indirect, real-time measure of native cardiac output during extracorporeal support [35], in survivors and non survivors.

\section{Main causes of deaths during ECPR}

The two main causes of death were early circulatory failure and delayed neurological damage. Patients dying from either cause had similar durations of low flow and mean $\mathrm{PaO}_{2}$, but initial lactate levels were lower in patients dying from neurological damage, pointing to less profound systemic anoxia. These patients also had higher mean blood pressure and required significantly less vasopressors. Overall, these findings suggest that patients with more severe anoxia (higher lactate levels) might develop more severe reperfusion injury under hyperoxic conditions, leading to predominantly vascular failure and early deaths, whereas those with less severe anoxia would survive the early stage and develop delayed hyperoxic neurological damage. This hypothesis should require validation in larger cohorts of patients treated with ECPR for refractory cardiac arrest.

$\mathrm{PaO}_{2}$ is the main variable associated with mortality in ECPR We did not find significant association between the initial rhythm and survival, which differs from the notion that survival under ECPR is better in patients with an initial shockable rhythm [36]. This discrepancy most likely reflects the small sample size in our study. Only $52 \%$ of patients had an initial shockable rhythm, and among those with a non-shockable rhythm, all patients with asystole died, whereas 3 out of 14 patients (21\%) with pulseless electrical activity (PEA) survived to hospital discharge. Interestingly, these 3 patients had the lowest mean $\mathrm{PaO}_{2}$ (152, 162 and $184 \mathrm{mmHg}$, respectively) among the 14 PEA patient, which may suggest that the avoidance of hyperoxia during ECPR could be critical to determine outcome in PEA patients undergoing ECPR.

Besides $\mathrm{PaO}_{2}$, survival in our cohort was significantly associated with the duration of low flow in univariate analysis, in line with previous investigations [37-39]. However, this association was not observed in a multivariable analysis evaluating several co-variates commonly associated with poor outcome after CA and ECPR, such as no flow, low flow, initial rhythm, localization of $\mathrm{CA}$ (IHCA vs OHCA) and age, together with mean $24 \mathrm{~h} \mathrm{PaO}_{2}$. We also included the duration of ECMO as a co-variate, given that the initial sweep gas oxygen fraction was set at $100 \%$, which could have favored persisting hyperoxia in these patients. With the exception of mean $\mathrm{PaO}_{2}$, none of these variables displayed a significant association with mortality. Although these findings may suggest a particularly negative prognostic implication of hyperoxia in ECPR, they warrant cautious interpretation. Owing to the relatively small sample size in our study, the results of multivariate analysis may be subject to some bias related to an overestimation of regression coefficients [18]. For this reason, we performed additional analyses using only one co-variate with mean $\mathrm{PaO}_{2}$, including no flow, low flow and initial rhythm, which confirmed the association of mean $\mathrm{PaO}_{2}$ with mortality. In addition, due to the retrospective nature of our study, the association of $\mathrm{PaO}_{2}$ with mortality could represent a surrogate for the sickness of patients. Physicians would indeed be inclined to maintain high levels of administered $\mathrm{O}_{2}$ to the most severely affected patients, and hyperoxia would therefore be a side effect of such management.

\section{Study limitations}

Our study has several limitations. First, we must acknowledge the usual limitations related to the retrospective design of our study [40] and to its relatively small sample size. Second, although we established an association between hyperoxia and mortality, as well with refractory circulatory failure, such associations do not necessarily mean a causal relationship. Third, the absence of internal recommendations for the management of arterial oxygen levels during ECPR may have favored the development of hyperoxia, which could have been avoided with a dedicated clinical protocol. Fourth, we relied on pulse pressure as an indirect evaluation of native cardiac output, which may be of limited reliability under conditions of 
varying cardiac loading conditions, especially afterload [41]. Direct assessment of native cardiac function using echocardiography would have been more appropriate in this setting, but we do not routinely perform echocardiography in the first $24 \mathrm{~h}$ after ECPR initiation. Fifth, we did not measure circulating mediators related to oxidative stress and inflammation, which could have given important insights on the effects of hyperoxic reperfusion during ECPR. Such measurements will be the matter of additional future investigations.

\section{Conclusion}

In conclusion, although we acknowledge several important limitations, our study shows that, in patients undergoing ECPR for refractory cardiac arrest, a high $\mathrm{PaO}_{2}$ during the first $24 \mathrm{~h}$ of support is associated with worse outcome, possibly by promoting severe vascular failure and refractory circulatory shock. $\mathrm{PaO}_{2}$ should therefore be strictly controlled during the first $24 \mathrm{~h}$ of ECPR, via blood sampling from the right radial artery. Future studies should evaluate the impact of different $\mathrm{PaO}_{2}$ levels during ECPR on biomarkers of oxidative stress and inflammation, to provide further insights into possible mechanisms of hemodynamic collapse in this setting.

\begin{abstract}
Abbreviations
ECMO: Extra-corporeal membrane oxygenation; VA-ECMO: Veno-arterial extracorporeal membrane oxygenation; ECPR: Extracorporeal cardiopulmonary resuscitation; CA: Cardiac arrest; OHCA: Out-of-hospital cardiac arrest; IHCA: Inhospital cardiac arrest; ROSC: Return of spontaneous circulation; ECLS: Extracorporeal life support; NA: Noradrenaline; Adre: Adrenaline; IV: Intravenous; PEEP: Positive end-expiratory pressure; BP: Blood pressure; PTCA: Percutaneous transluminal coronary angioplasty; FFP: Fresh frozen plasma; RBC: Red blood cells; RA: Radial artery; SAPS: Simplified acute physiology score; VF: Ventricular fibrillation; LOS: Length of stay.
\end{abstract}

\section{Supplementary Information}

The online version contains supplementary material available at https://doi. org/10.1186/s12872-021-02361-3.

Additional file 1:Supplementary Table 1. Study data set.

\section{Acknowledgements}

Not applicable.

\section{Authors' contributions}

JB: Data acquisition and analysis; Interpretation of data; Writing: original draft. MR: Data acquisition and analysis; Interpretation of data; Writing: review and editing. ZL: Data acquisition and analysis; Interpretation of data; Writing: review and editing. AR: Data acquisition and analysis; Interpretation of data; Writing: review and editing. PT: Data acquisition and analysis; Interpretation of data; Writing: review and editing. MO: Conception and design of the work; Project administration; Interpretation of data; Writing: review and editing. MK: Conception and design of the work; Project administration; Interpretation of data; Writing: review and editing. LL: Conception and design of the work; Project administration; Data acquisition and analysis; interpretation of data; Writing: original draft. All authors read and approved the final manuscript.

\section{Funding}

Dr. J.B. is supported by a grant from the Emma Muschamp Foundation, Lausanne, Switzerland, and the Mahmoud Darvish Foundation, Lausanne Switzerland.

\section{Availability of data and materials}

All data generated or analysed during this study are included in this published article and its Additional file 1:Table 1.

\section{Declarations}

Ethics approval and consent to participate

Ethical Committee Name: Commission Cantonale d'Ethique de la Recherche sur l'Etre Humain (CER-VD). Retrospective use of clinical data with waiver of consent (Approval number: CER-VD-Nr: 2017-01184).

\section{Consent for publication}

Not applicable.

\section{Competing interests}

The authors declare that they have no competing interests.

\section{Author details}

${ }^{1}$ The Service of Adult Intensive Care Medicine, Lausanne University Hospital and University of Lausanne, Rue du Bugnon 46, 1011 Lausanne, Switzerland.

${ }^{2}$ The Service of Cardiac Surgery, Lausanne University Hospital and University of Lausanne, Rue du Bugnon 46, 1011 Lausanne, Switzerland.

Received: 1 June 2021 Accepted: 3 November 2021

Published online: 14 November 2021

References

1. Fagnoul D, Combes A, De Backer D. Extracorporeal cardiopulmonary resuscitation. Curr Opin Crit Care. 2014;20(3):259-65.

2. Patricio D, Peluso L, Brasseur A, Lheureux O, Belliato M, Vincent $J$, et al. Comparison of extracorporeal and conventional cardiopulmonary resuscitation: a retrospective propensity score matched study. Crit Care. 2019;23(1):27.

3. Bougouin W, Dumas F, Lamhaut L, Marijon E, Carli P, Combes A, et al. Extracorporeal cardiopulmonary resuscitation in out-of-hospital cardiac arrest: a registry study. Eur Heart J. 2020;41(21):1961-71.

4. Lunz D, Calabro L, Belliato M, Contri E, Broman LM, Scandroglio AM, et al. Extracorporeal membrane oxygenation for refractory cardiac arrest: a retrospective multicenter study. Intensive Care Med. 2020;46(5):973-82.

5. Dennis M, Lal S, Forrest P, Nichol A, Lamhaut L, Totaro RJ, et al. In-depth extracorporeal cardiopulmonary resuscitation in adult out-of-hospital cardiac arrest. J Am Heart Assoc. 2020;9(10):e016521.

6. MacLaren G, Masoumi A, Brodie D. ECPR for out-of-hospital cardiac arrest: more evidence is needed. Crit Care. 2020;24(1):7.

7. Inoue A, Hifumi T, Sakamoto T, Kuroda Y. Extracorporeal cardiopulmonary resuscitation for out-of-hospital cardiac arrest in adult patients. J Am Heart Assoc. 2020;9(7):e015291.

8. McKenzie NF, Dobb GJ. Oxygen after cardiac arrest: enough is enough? Circulation. 2018;137(20):2125-7.

9. Pilcher J, Weatherall M, Shirtcliffe P, Bellomo R, Young P, Beasley R. The effect of hyperoxia following cardiac arrest—a systematic review and meta-analysis of animal trials. Resuscitation. 2012;83(4):417-22.

10. Kilgannon JH, Jones AE, Shapiro NI, Angelos MG, Milcarek B, Hunter K, et al. Association between arterial hyperoxia following resuscitation from cardiac arrest and in-hospital mortality. JAMA. 2010;303(21):2165-71.

11. Roberts BW, Kilgannon JH, Hunter BR, Puskarich MA, Pierce L, Donnino M, et al. Association between early hyperoxia exposure after resuscitation from cardiac arrest and neurological disability: prospective multicenter protocol-directed cohort study. Circulation. 2018;137(20):2114-24.

12. Hutin A, Abu-Habsa M, Burns B, Bernard S, Bellezzo J, Shinar Z, et al. Early ECPR for out-of-hospital cardiac arrest: best practice in 2018. Resuscitation. 2018;130:44-8. 
13. Halter M, Jouffroy R, Saade A, Philippe P, Carli P, Vivien B. Association between hyperoxemia and mortality in patients treated by eCPR after out-of-hospital cardiac arrest. Am J Emerg Med. 2020;38(5):900-5.

14. Chang WT, Wang CH, Lai CH, Yu HY, Chou NK, Wang CH, et al. Optimal arterial blood oxygen tension in the early postresuscitation phase of extracorporeal cardiopulmonary resuscitation: a 15-year retrospective observational study. Crit Care Med. 2019;47(11):1549-56.

15. Miroz JP, Ben-Hamouda N, Bernini A, Romagnosi F, Bongiovanni F, Roumy $A$, et al. Neurological pupil index for early prognostication after venoarterial extracorporeal membrane oxygenation. Chest. 2020;157(5):1167-74.

16. Tsetsou S, Novy J, Pfeiffer C, Oddo M, Rossetti AO. Multimodal outcome prognostication after cardiac arrest and targeted temperature management: analysis at $36^{\circ} \mathrm{C}$. Neurocrit Care. 2018;28(1):104-9.

17. Mourad M, Eliet J, Zeroual N, Saour M, Sentenac P, Manna F, et al. Pulse pressure and end-tidal carbon dioxide for monitoring low native cardiac output during veno-arterial ECLS: a prospective observational study. Crit Care. 2020;24(1):569.

18. Steyerberg EW, Eijkemans MJ, Habbema JD. Stepwise selection in small data sets: a simulation study of bias in logistic regression analysis. J Clin Epidemiol. 1999;52(10):935-42.

19. Johnson NJ, Carlbom DJ, Gaieski DF. Ventilator management and respiratory care after cardiac arrest: oxygenation, ventilation, infection, and injury. Chest. 2018;153(6):1466-77.

20. Fridovich I. Quantitative aspects of the production of superoxide anion radical by milk xanthine oxidase. J Biol Chem. 1970;245(16):4053-7.

21. Di Maria CA, Bogoyevitch MA, McKitrick DJ, Arnolda LF, Hool LC, Arthur PG. Changes in oxygen tension affect cardiac mitochondrial respiration rate via changes in the rate of mitochondrial hydrogen peroxide production. J Mol Cell Cardiol. 2009;47(1):49-56.

22. Carnesecchi S, Deffert C, Pagano A, Garrido-Urbani S, MetraillerRuchonnet I, Schappi M, et al. NADPH oxidase-1 plays a crucial role in hyperoxia-induced acute lung injury in mice. Am J Respir Crit Care Med. 2009;180(10):972-81.

23. Llitjos JF, Cariou A. Hyperoxia in post-cardiac arrest: friend or foe? J Thorac Dis. 2018;10(Suppl 33):S3908-10.

24. Munshi L, Kiss A, Cypel M, Keshavjee S, Ferguson ND, Fan E. Oxygen thresholds and mortality during extracorporeal life support in adult patients. Crit Care Med. 2017:45(12):1997-2005.

25. Pacher P, Beckman JS, Liaudet L. Nitric oxide and peroxynitrite in health and disease. Physiol Rev. 2007:87(1):315-424.

26. Liaudet $L$, Rosenblatt-Velin N, Pacher P. Role of peroxynitrite in the cardiovascular dysfunction of septic shock. Curr Vasc Pharmacol. 2013;11(2):196-207

27. Liaudet L, Soriano FG, Szabo E, Virag L, Mabley JG, Salzman AL, Szabo C. Protection against hemorrhagic shock in mice genetically deficient in poly(ADP-ribose)polymerase. Proc Natl Acad Sci USA. 2000;97(18):10203-8.

28. Damiani E, Adrario E, Girardis M, Romano R, Pelaia P, Singer M, Donati A. Arterial hyperoxia and mortality in critically ill patients: a systematic review and meta-analysis. Crit Care. 2014;18(6):711.
29. Nagato AC, Bezerra FS, Lanzetti M, Lopes AA, Silva MA, Porto LC, Valenca SS. Time course of inflammation, oxidative stress and tissue damage induced by hyperoxia in mouse lungs. Int J Exp Pathol. 2012;93(4):269-78.

30. Helmerhorst HJF, Schouten LRA, Wagenaar GTM, Juffermans NP, Roelofs J, Schultz MJ, et al. Hyperoxia provokes a time- and dose-dependent inflammatory response in mechanically ventilated mice, irrespective of tidal volumes. Intensive Care Med Exp. 2017;5(1):27.

31. Lugrin J, Rosenblatt-Velin N, Parapanov R, Liaudet L. The role of oxidative stress during inflammatory processes. Biol Chem. 2014;395(2):203-30.

32. Jouffroy R, Guyard A, Philippe P, Carli P, Vivien B. Effect of mean blood pressure during extracorporeal life support on outcome after out-ofhospital cardiac arrest. Turk J Anaesthesiol Reanim. 2019;47(2):134-41.

33. Rao P, Khalpey Z, Smith R, Burkhoff D, Kociol RD. Venoarterial extracorporeal membrane oxygenation for cardiogenic shock and cardiac arrest. Circ Heart Fail. 2018;11(9):e004905.

34. Roumy A, Liaudet L, Rusca M, Marcucci C, Kirsch M. Pulmonary complications associated with veno-arterial extra-corporeal membrane oxygenation: a comprehensive review. Crit Care. 2020;24(1):212.

35. Rilinger J, Riefler AM, Bemtgen X, Jackel M, Zotzmann V, Biever PM, et al. Impact of pulse pressure on clinical outcome in extracorporeal cardiopulmonary resuscitation (eCPR) patients. Clin Res Cardiol. 2021;110:1473-83.

36. De Charriere A, Assouline B, Scheen M, Mentha N, Banfi C, Bendjelid K, Giraud R. ECMO in cardiac arrest: a narrative review of the literature. J Clin Med. 2021;10(3):534.

37. Otani T, Sawano H, Natsukawa T, Nakashima T, Oku H, Gon C, et al. Low-flow time is associated with a favorable neurological outcome in out-of-hospital cardiac arrest patients resuscitated with extracorporeal cardiopulmonary resuscitation. J Crit Care. 2018;48:15-20.

38. Wengenmayer T, Rombach S, Ramshorn F, Biever P, Bode C, Duerschmied D, Staudacher DL. Influence of low-flow time on survival after extracorporeal cardiopulmonary resuscitation (eCPR). Crit Care. 2017:21(1):157.

39. Yu HY, Wang CH, Chi NH, Huang SC, Chou HW, Chou NK, Chen YS. Effect of interplay between age and low-flow duration on neurologic outcomes of extracorporeal cardiopulmonary resuscitation. Intensive Care Med. 2019;45(1):44-54

40. Tofthagen C. Threats to validity in retrospective studies. J Adv Pract Oncol 2012;3(3):181-3.

41. Rilinger J, Riefler AM, Bemtgen X, Jackel M, Zotzmann V, Biever PM, et al. Impact of pulse pressure on clinical outcome in extracorporeal cardiopulmonary resuscitation (eCPR) patients. Clin Res Cardiol. 2021;110(9):1473-83.

\section{Publisher's Note}

Springer Nature remains neutral with regard to jurisdictional claims in published maps and institutional affiliations.

\footnotetext{
Ready to submit your research? Choose BMC and benefit from:

- fast, convenient online submission

- thorough peer review by experienced researchers in your field

- rapid publication on acceptance

- support for research data, including large and complex data types

- gold Open Access which fosters wider collaboration and increased citations

- maximum visibility for your research: over $100 \mathrm{M}$ website views per year
}

At BMC, research is always in progress.

Learn more biomedcentral.com/submissions 